\title{
LXXXV. Notes on the preparation of alloxan
}

\section{William Gregory M.D. F.R.S.E.}

To cite this article: William Gregory M.D. F.R.S.E. (1846) LXXXV. Notes on the preparation of alloxan, Philosophical Magazine Series 3, 28:190, 550-554, DOI: $10.1080 / 14786444608645469$

To link to this article: http://dx.doi.org/10.1080/14786444608645469

曲 Published online: 30 Apr 2009.

Submit your article to this journal $2 \pi$

Џ Article views: 2

Q View related articles $₫$ 


\section{Measurements of Guanite.}

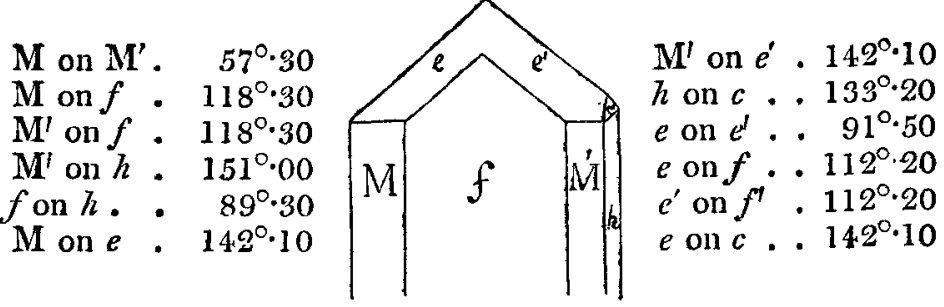

LXXXV. Notes on the Preparation of Alloxan. By William Gregory, M.D., F.R.S.E.*

$\mathrm{N}$ an interesting and able paper on alloxan and its derivatives, the first part of which appears in Liebig's $A m$. nalen for September 1845, Schlieper enters into minute details concerning the most advantageous method of preparing alloxan, and after describing the results which he obtained on repeating the process given by me, proposes a new method of his own, which be consider's in every way preferable, as yielding, with greater facility and certainty, a larger proportion of alloxan. Professor Liebiy in his Lectures (Lancet 184.5) also recommends Schlieper's method as the best in every respect.

I am still, notwithstanding, inclined to give a decided preference to my own process, when carefully performed, and that on the grounds of its superior simplicity, facility and productiveness. A brief comparison of the two methods, with their results, will enable the reader to judge for himself.

I must first of all, however, observe, that Scblieper, in repeating my process, has not obtained results so favourable as I had formerly announced; so that, in his hands, his own method has been the more productive. I formerly obtained from 100 parts of uric acid 90 of crystallized (hydrated) alloxan, perfectly pure, not reckoning the portion of alloxan remaining in the mother-liquids. Schlieper, on the other hand, from 15 ounces of uric acid, treated by my process, obtained, including the contents of the mother-liquids, 8 ounces hydrated alloxan, $1 \frac{3}{4}$ ounce alloxantine $\left(=2 \frac{1}{4}\right.$ ounces alloxan $)$, and $\frac{3}{4}$ onnce parabanic acid ; in all equivalent to about $11 \frac{1}{4}$ ounces of alloxan. This only amounts to 75 per cent.; whereas I obtained 90 per cent., exclusive of the mother-liquids, which I find on an average to yield fully one-tenth mose; in all, therefore, at least 100 per cent. I may here state that I have

- Conmunicated by the Chenical Suciety; having been read December 15,1845 . 
never failed to obtain this as an average result since my process was published, although I have very often repeated the process. Several of my pupils have been equally successful. I shall now, therefore, describe the process as I have for some time pursued it, and its simplicity will, I trust, be evident.

In my original account of this process, I recommended the use of nitric acid of sp. gr. 1.3 to 1.95, and it was with such acid, as $I$ believed, that my results were obtained. But as Schlieper found it impossible to succeed with acid of less sp. gr. than $1 \cdot 4$ to $1 \cdot 42$, I suspect that I may have been mistaken as to the sp. gr. of my acid. This I cannot now ascertain; but it is rendered probable by the circumstance that, in the experiments about to be mentioned, I found an acid of 1.412 to answer my purpose perfectly, with the same appearances as I had formerly observed.

Schlieper having corrected this error proceeds to describe my process, as performed by him, with great accuracy and minuteness, and his description of the phænomena entirely agrees with my experience. I can only account for his not obtnining such favourable results as I have al ways done, to the circumstance of his acid being a little too concentrated. However this may be, on reading his paper I proceeded to repeat my process, and obtained the results to be hereafter stated.

The following is the process I now follow: -2 or $2 \frac{1}{2}$ fluid ounces of colourless nitric acid, sp. gr. 1.412 , are placed in a flat-bottomed dish or beaker glass, and as much uric acid is introduced as will lie on the point of a small spatula. This is well-stirred in to prevent the formation of lumps, and in a few minutes effervescence commences, the liquid becomes slightly warm, and the powder dissolves. More uric acid is now added, taking care never to exceed a certain small quantity, and not to allow the liquid to become warm beyond a certain degree, which is easily judged of by laying the dish on the hand. If too hot when uric acid is added, or if too much acid be added at once, the uniform stendy effervescence is changed into a violent and tumultuous action, after which no alloxan can be obtained. It is proper to have a plate with cold water at hand, in which to place the dish or glass if it should seem likely to become too warm. But a little practice enables us to regulate the operation so that no external cooling is required.

After several portions of uric acid have been added, crystals of alloxan begin to appear in the warm liquid, bat the addition of uric acid is to be continued, with the same precautions, till so much alloxan has been formed, that on cooling the whole becomes nearly semisolid. When this point is reached 
the liquid has become somewhat viscid, and this, along with the presence of the crystalline deposit of alloxan, gives a peculiar character to the effervescence toward the end of the operation. I commonly find that with $2 \frac{1}{2}$ fluid ounces of nitric acid the point above alluded to is reached when about 1200 grains of uric acid dried at $212^{\circ}$ have been dissolved. It does not answer to operate on a much larger scale; it is better to use several dishes at once, each containing $2 \frac{1}{2}$ or at the most 3 fluid ounces of acid. For every 500 grains of uric acid 1 fluid ounce of nitric acid may be allowed.

The whole is now allowed to stand all night in a cool place, and next day the alloxan is collected on a funnel with the aid of a little asbestus. The mother-liquid drains off, and the last portions of it are cautiously displaced by ice-cold water, till the droppings are found to have only a moderately strong acid taste. The alloxan on the funnel, which is anhydrous, is then digested with just as much water at $140^{\circ}$ or $150^{\circ} \mathrm{F}$. as will dissolve it. The solution is filtered, and on cooling deposits a large crop of crystals of hydrated alloxan. [Should too much water have been added, the filtered liquid must be evaporated at from $120^{\circ}$ to $140^{\circ} \mathrm{F}$, till on cooling it crystallizes abundantly.] The mother-liquid of these crystals, evaporated at the same temperature, yields a second crop. The mother-liquor of this is added to the acid mother-liquor previously drained off, and the whole liquid treated, after the addition of two or three times its bulk of water, with sulphuretted hydrogen, till the alloxan present is reduced to the state of alloxantine. As a part is always reduced still further to dialuric acid, the liquid must be exposed to the air for a day or two, or until it deposits no more crystals. The alloxantine is purified by solution in boiling water, filtration to separate sulphur, and crystallization; and when dry three parts of it correspond to rather more than four of hydrated alloxan. If required, it may very easily be converted into alloxan; as Schlieper has described this process I need not repeat it here.

The mother-liquid of the alloxantine generally yields some parabanic acid; but very little if the process has been carefully performed.

I think it will be admitted that the above process is sufficiently simple. It will be observed that I no longer recommend the separation of the alloxan formed from the nitric acid in several successive portions, but that there is only one operation for all, in which the alloxan is collected on a funnel with asbestus. I used sometimes to divide the process into five successive operations, and generally made three of them: but $I$ am now convinced that it is best to dissolve in the nitric 
acid the whole of the uric acid that is to be dissolved before collecting the alloxan.

Let us now consider the productiveness of this method. I have already stated my average of former results to have been 90 per cent. of crystallized alloxan, exclusive of the motherliquid, which corresponded to one-tenth more. As the process now stands we have-1. The first crop of crystals of alloxan, varying with the proportion of water used to dissolve the anhydrous alloxan. 2. The second crop of the same crystals. 3. The alloxantine from the mother-liquid converted into alloxan, or calculated in that form. I take no account of the parabanic acid.

Experiment 1.-Uric acid 2600 grains; alloxan, first crop, 1950 grains, second crop, 550 grains ; alloxantine, 200 grains, equivalent to alloxan, 290 grains. In all, therefore, from 2600 grains of uric acid, 2790 grains of hydrated alloxan, or 107 per cent. nearly.

Experiment 2.-Uric acid, 1130 grains; alloxan, first crop, 800 grains, second crop, 140 grains; alloxantine, 80 grains, equivalent to alloxan, 116 grains. In all, therefore, $1056 \mathrm{grs}$. of alloxan from 1130 of uric acid, or 93 per cent.

Experiment 3.-Uric acid, 1500 grains ; alloxan, first crop, 1150 grains, second crop, 270 grains; alloxantine, 120 grains, equivalent to alloxan, 174 grains. In all, therefore, from 1500 grains of uric acid, 1594 grains of alloxan, or 106 per cent.

The above results, averaging 102 per cent. of pure hydrated alloxan, were obtained without difficulty. Indeed the only delicate point in the process is the attention necessary to avoid too great a rise in temperature, alloxan being decomposed by heat even when simply dissolved in water, but still more when acid is present. A little experience however makes this quite easy ; and besides, this difficulty attaches equally to Schlieper's new method, as we shall see.

The formula of uric acid being $\mathrm{C}_{10} \mathrm{~N}_{4} \mathrm{H}_{4} \mathrm{O}_{6}$, while that of hydrated alloxan is $\mathrm{C}_{8} \mathrm{~N}_{2} \mathbf{H}_{4} \mathrm{O}_{10}+6$ aq, it is obvious that 100 parts of uric acid can produce about 128 of alloxan. It is not likely that we shall ever obtain the full proportion with. out loss, but I consider my process, simple as it is, to furnish a very satisfactory approximation, considering the impossibility of separating the whole alloxan from the acid liquid in which it is formed.

If we now refer to Schlieper's account of his new method, we find that it includes the following operations:-1. The uric acid is acted on by hydrochloric acid and chlorate of potash, care being necessary, as in my process, to keep the

Phil. Mag. S. 3. No. 190. Suppl. Vol. 28.

$2 \mathrm{P}$ 
temperature below a certain point. 2. The whole of the alloxan is reduced by sulphuretted hydrogen to the state of alloxantine. 3. The alloxantine is reoxidized by nitric acid, and thus reconverted into alloxan. I cannot admit that this process is either more simple or more easy than my own. On the contrary, as I obtain nine-tenths of the whole alloxan, or 90 parts from 100 of uric acid directly as alloxan, and pure, in the first crystallizations, while Schlieper first converts all his alloxan into alloxantine, and then reconverts the alloxantine into alloxan; and further, as I use no other reagent but nitric acid in preparing these nine-tenths, the advantage of simplicity and facility is entirely on my side.

From 4 ounces of uric acid, Schlieper obtains by his own process 2 ounces 7 drachms and 20 grains of alloxantine, equivalent theoretically to 3 ounces and 7 drachms of alloxan, or nearly 97 per cent. But in reconverting this alloxantine into alloxan by nitric acid, it will be found impossible to obtain, practically, the whole alloxan, since some of it must re. main in the mother-liquid; and moreover, in the process of oxidation by heating with nitric acid some alloxan is very likely to be converted into parabanic acid, and thus lost. Judging from experience, I should not expect the 97 per cent. of alloxan obtained in theory to yield, in crystals, more than 90 per cent.

As far as productiveness, therefore, is concerned, I may claim also a superiority for my method. It is true that it has not succeeded so well in the hands of Schlieper, but this must I think be attributed to accidental causes, and possibly to a want of perfect familiarity with the method on the part of Schlieper, who seems to be so good an operator, that I cannot doubt that he would, after a little practice, obtain the same results as I have always succeeded in obtaining.

Finally, I beg to remind those who may wish to try my process, that what Schlieper describes as a modification of my process is the process itself, unmodified; because the only change introduced by Schlieper consists in the use of acid at 1.4 or 1.42 instead of 1.3 or 1.35 , as erroneously recommended in my original process. In point of fact, the acid which I have long used for the purpose has the sp. gr. 1·412, and for this number 1.3 or 1.35 was accidentally substituted in writing or printing my former notice. In common with all chemists I am much indebted to M. Schlieper for pointing out this oversight. 